\title{
EVALUASI KONSEP KAWASAN TRANSIT ORIENTED DEVELOPMENT (TOD) STASIUN CISAUK, KECAMATAN CISAUK, KABUPATEN TANGERANG, BANTEN. (STUDI KASUS STASIUN CISAUK, KECAMATAN CISAUK, KABUPATEN TANGERANG)
}

\author{
Beryllium Safiullah Ahmad ${ }^{1)}$, Sylvie Wirawati ${ }^{2)}$, B. Irwan Wipranata ${ }^{3)}$ \\ 1)Program Studi S1 PWK, Fakultas Teknik, Universitas Tarumanagara, berryllium.12@gmail.com \\ 2) Program Studi S1 PWK, Fakultas Teknik, Universitas Tarumanagara, sylview@ft.untar.ac.id \\ 3)Program Studi S1 PWK, Fakultas Teknik, Universitas Tarumanagara, irwan_wipranata@yahoo.co.uk
}

\begin{abstract}
Abstrak
Pengembangan kota dengan konsep Transit Oriented Development (TOD) merupakan pengembangan kota yang bertumpu pada moda transportasi massal, konsep Transit Oriented Development (TOD) di Kota yaitu sebagai penyangga lbukota terhadap kota - kota yang berada di sekitar pusat kota. Belakangan ini Transit Oriented Development (TOD) menjadi solusi untuk mengintergrasikan hunian dengan transportasi massal sehingga memudahkan akses menuju ibukota, dalam pengembangan Transit Oriented Development (TOD) terdapat standar khusus yang mengikuti kriteria standar penilaian baik secara nasional maupun internasional. Transit Oriented Development Stasiun Cisauk merupakan salah satu Transit Oriented Development yang sedang dikembangkan di Kabupaten Tangerang, sekaligus sebagai Kota Penyangga Ibukota. Tujuan penelitian ini untuk menganalisis kesesuaian pengembangan kawasan Transit Oriented Development (TOD) Stasiun Cisauk baik berdasarkan Peraturan Rencana Tata Ruang Wilayah (RTRW) Kabupaten Tangerang 2011 - 2031 maupun berdasarkan kriteria Standard Institute for Transportation and Development Policy (ITDP) untuk mengetahui kesesuaian kawasan Transit Oriented Development (TOD) Stasiun Cisauk. Berdasarkan hasil dari evaluasi analisis scorecard dengan menggunakan metode kualitatif komparatif menghasilkan kesesuaian Proyek Transit Oriented Development (TOD) Stasiun Cisauk terhadap kriteria Standard Institute For Transportation and Development Policy (ITDP) dengan aspek berjalan/walk, bersepeda/cycle, menghubungkan/connect, angkutan umum/transit, pembauran/mix, memadatkan/densify, merapatkan/compact, dan beralih/shift, maka Transit Oriented Development (TOD) Stasiun Cisauk sudah memenuhi kriteria standar Transit Oriented Development TOD) dan memiliki nilai persentase $55 \%$ - 69\% dari 100\% penilaian. Peneliti mengetahui bahwa hasil evaluasi Transit Oriented Development (TOD) Stasiun Cisauk masuk dalam katagori kriteria kelas penilaian Bronze, hasil ini di dapatkan oleh peneliti dengan mengkomparatifkan data hasil penelitian dan kriteria penilaian berdasarkan International Institute For Transportation and Development Policy (ITDP).
\end{abstract}

Kata Kunci : Evaluasi; Transit Oriented Development; Kriteria Standard Institute For Transportation and Development Policy; Stasiun Cisauk

\begin{abstract}
City development with the concept of Transit Oriented Development (TOD) is a city development that relies on mass transportation modes, the concept of Transit Oriented Development (TOD) in the City, namely as a buffer for the capital against cities that are around the city center. Recently, Transit Oriented Development (TOD) has become a solution to integrate housing with mass transportation so as to facilitate access to the capital, in the development of Transit Oriented Development (TOD) there are special standards that follow standard assessment criteria both nationally and internationally. Transit Oriented Development Cisauk Station is one of the Transit Oriented Developments being developed in Tangerang Regency, as well as the Capital City Supporting City. The purpose of this study is to analyze the suitability of the development of the Transit Oriented Development (TOD) area of Cisauk Station, both based on the Tangerang Regency Spatial Planning (RTRW) Regulations 2011-2031 and based on the criteria of the Standard Institute for Transportation and Development Policy (ITDP) to determine the suitability of the Transit Oriented area. Development
\end{abstract}


(TOD) Cisauk Station. Based on the results of the evaluation of theanalysis scorecard using comparative qualitative methods resulted in the suitability of theProject of Transit Oriented Development (TOD)Cisauk Station against theof criteriathe Standard Institute For Transportation and Development Policy (ITDP) with aspects of walking/walking, cycling/cycle, connecting/connecting, public transportation/transit, mixing, compressing, compacting, and shifting, then the Transit Oriented Development (TOD) of Cisauk Station has met the standard criteria for Transit Oriented Development TOD) and has a percentage value of 55\% - 69\% from 100\% assessment. The researcher knows that the results of the evaluation of the Transit Oriented Development (TOD) Cisauk Station are included in the category of theassessment class criteria Bronze, this result was obtained by the researchers by comparing the research data and the assessment criteria based on the International Institute For Transportation and Development Policy (ITDP).

Keywords: Evaluation; Transit Oriented Development; Criteria Standard Institute For Transportation and Development Policy (ITDP); Cisauk Station.

\section{PENDAHULUAN}

\section{Latar Belakang}

Pengembangan kawasan yang berorientasi dengan transit merupakan salah satu solusi transportasi dalam lingkungan di kawasan perkotaan modern saat ini. Terutama pengembangan yang dilakukan dikota - kota besar yang berpusat pada Central Business District (CBD) yang memiliki bangunan - bangunan tinggi komersial untuk menjadi pusat mobilitas masyarakat seperti DKI Jakarta dan perumahan - perumahan modern dengan konsep kota mandiri. Tujuan pengembangan Transit Oriented Devlopment (TOD) oleh kota - kota besar yang berada di Indonesia terutama pada pengembangan kawasan kota mandiri untuk mengatasi permasalahan kemacetan melalui sebuah integrasi dalam sistem jaringan transportasi masal yang dimana tujuan utama dari TOD ini untuk mengurangi penggunaan kendaraan pribadi agar masyarakat lebih menggunakan kendaraan umum dan berjalan kaki untuk melakukan kegaiatan rutinitas masyarakat

Pengembangan TOD ini adalah untuk mengalihkan sebagian besar pengguna kendaraan pribadi ke angkutan umum atau ke angkutan umum yang berbasis rel, karena tujuan utama dari konsep pengembangan ini yaitu untuk mengurangi kemacetan akibat penggunaan kendaraan pribadi. Perkembangan kawasaan - kawasan kota mandiri di Jabodetabek memiliki dampak bagi masyarakat yang tinggal di pinggiran perkotaan membuat mobilitas semakin tinggi yang menjadikan kemacetan semakin meningkat. Kebutuhan hunian di area pinggiran perkotaan harus didorong dengan suatu penunjang sarana dan prasarana seperti akses yang terjangkau untuk ketempat kerja, fasilitas yang saling terintegrasi dengan angkutan umum, prasarana yang menunjang.Stasiun Cisauk merupakan kawasan pengembangan Transit Oriented Development (TOD) yang berlokasi di kecamatan Cisauk, Kawasan TOD tersebut memiliki pertumbuhan penduduk yang cukup pesat dari tahun ke tahun menimbulkan kepadatan penduduk menjadi tinggi karena kurangnya pembangunan infrastruktur dasar yang merata dikawasan Stasiun Cisauk.

Letak posisi Stasiun Cisauk yang strategis menimbulkan banyaknya pembangunan hunian di sekitar Stasiun Cisauk, Pemerintah Kabupaten Tangerang melakukan segala upaya untuk pembangunan fasilitas infrastruktur, perekonomian ataupun pemerintahan yang berlokasi disekitar Stasiun Cisauk agar pembangunan merata. Berbagai macam rencana dan upaya untuk pembangunan daerah yang lebih berkualitas dengan adanya konsep TOD di kawasan Stasiun Cisauk.

Dengan adanya pembangunan Kawasan TOD yang berada di Stasiun Cisauk ini diharapkan mampu menunjang kebutuhan masyarakat untuk melakukan aktivitas sehari - hari. 
Pengembangan Kawasan Transit Oriented Development (TOD) ini diharapkan masyarakat Sekitar Stasiun Cisauk dapat mencapai tujuan dengan moda transportasi angkutan umum khususnya berbasis rel yang dapat ditempuh dengan berjalan kaki atau dengan bersepeda ke lokasi stasiun. Dalam area TOD ini diharapkan terciptanya kawasan mixed-use di sekitar Stasiun Cisauk yang saling terintegrasi antara pusat perbelanjaan, kantor, hunian, daerah komersial, dan fasilitas lainnya.

\section{Rumusan Permasalahan}

(1) Rumusan permasalahan dalam penelitian ini adalah Terdapatnya kepadatan volume lalu lintas kendaraan yang berada di Kawasan TOD Stasiun Cisauk; (2) Apakah Sudah Sesuai konsep kawasan Transit Development (TOD) stasiun cisauk dengan standard Institute For Transportation Development Policy (ITDP) dan Permen ATR/BPN No.16 Tahun 2017 ; (3) bagaimana karakteristik lahan kawasan Transit Oriented Development (TOD) stasiun cisauk ; (4) bagaimana kesesuaian rencana kota dan regulasi kota dalam konsep kawasan Transit Oriented Development (TOD) stasiun cisauk.

\section{Tujuan}

(1) Mengetahui potensi dan masalah Transit Oriented Development (TOD) stasiun cisauk ;

(2) Mengetahui apakah Kawasan Transit Oriented Development (TOD) stasiun cisauk sudah memenuhi kriteria Standard Institute For Transportation and Development Policy (ITDP) dan peraturan Menteri ATR/BPN ; (3) mendapatkan hasil dan diskusi dari penelitian konsep Transit Oriented Development (TOD) stasiun cisauk.

\section{KAJIAN LITERATUR}

\section{Sejarah Konsep Transit Oriented Development (TOD)}

Konsep Transit Oriented Development (TOD) merupakan konsep pengembangan kawasan transit yang bersinergi dengan lingkungan, dimana lebih mengedepankan konsep ramah lingkungan dengan memaksimalkan pedestrian dan mengurangi penggunaan kendaraan (Calthorpe, 1993). Lahirnya konsep Transit Oriented Development tidak lepas dari sejarah perkembangan kota metropolitan yang menyangkut konsep dalam kota, dan konsep lingkungan ekologis sekitarnya yang berkaitan erat dengan konsep moda transportasi. Perbedaan paradigma dalam memandang konsep kota modern berbasis mobil dan kendaraan publik memunculkan perbedaan pandangan dalam memandang hubungan kota dengan kegiatan transit. Pengunaan transportasi publik secara masal mulai di perkenalkan di Amerika Serikat pada apada awal abad ke 20. Fase transit pertama pada konsep ini berorentasi pada pengembangan atau yang dikenal dengan transit oriented development, dimana pada fase ini ditandai dengan karakter adanya zona pemukiman terpisah dari zona kerja yang diitegrasikan oleh transportasi masal seperti trem dan kereta api(Dittmar, Hank, and Gloria Ohland, 2012). Untuk meningkatkan hubungan yang intens dan kompleks antara penggunaan lahan dan transportasi permintaan, dalam beberapa dekade terakhir telah dikembangkan beberapa jenis pembangunan perkotaan. Salah satunya adalah TOD (TransitOriented Development), yang terdiri dari pemusatan pengembangan perkotaan di sekitar stasiun dalam rangka mendukung penggunaan transit, dan pengembangan transit sistem untuk menghubungkan konsentrasi pembangunan yang ada dan yang direncanakan(Aracil, 2017).

TOD adalah proses pemfokusan pembangunan perumahan, lapangan kerja, lokasi kegiatan dan layanan dan fasilitas umum di sekitar stasiun atau pemberhentian kereta api atau bus rapid transit yang ada atau baru(Knowles \& Ferbrache, 2013). Dengan kepemilikan dan penggunaan mobil massal, dan kemacetan lalu lintas jalan perkotaan, beberapa kegiatan ekonomi telah dipindahkan ke lokasi yang lebih mudah diakses di pinggiran kota di kota tepi 
atau pusat kota pinggiran kota (Garreau, 2011); (Hartshorn, 1992). TOD meningkatkan aksesibilitas dan meningkatkan aktivitas dan penggunaan lahan di sekitar stasiun transit dan pemberhentian, dan di CBD. (Geurs \& van Wee, 2004) mendefinisikan aksesibilitas sebagai 'sejauh mana penggunaan lahan dan sistem transportasi memungkinkan (kelompok) individu untuk mencapai kegiatan atau tujuan melalui (kombinasi) moda transportasi'. Waktu perjalanan dan biaya keduanya merupakan elemen kunci dalam pilihan moda individu (Banister, 2011).

Menurut (Calthorpe, 1993) konsep transit oriented development (TOD) merupakan salah satu alternatif dalam suatu perencanaan tata kota untuk pengembangan suatu daerah. Pengembangan kota yang berorentasi pada transit oriented development dapat berpotensi meningkatkan kulitas hidup masyarakat, serta dapat mengurangi biaya transfortasi dan masalah psikologi masayarakat perkotaan yang mempunyai masalah dengan adanya fenomena urban sprawl. Sedangkan keuntungan yang didapat oleh suatu daerah atau kawasan yang mengembangkan transit oriented development dengan pola ruang mixeduse dapat mengurangi dampak lingkungan, efisiensi pengelolaan lahan dan sebagai alternatif untuk mengurangi kemacetan lalu lintas yang semakin hari terus berkembang, inefisiensi biaya transportasi, mengurangi polusi CO2 karena banyaknya masyarakat menggunakan kendaraan pribadi.

\section{Tipologi Transit Oriented Development (TOD)}

Menurut (Calthorpe, 1993) Tipologi kawasan TOD dilakukan berdasarkan skala pelayanan sistem transportasi massal, pengembangan pusat pelayanan dan kegiatan yang dikembangkan. Berdasarkan pengertian diatas, tipologi TOD terdiri atas; pertama kawasan TOD perkotaan seperti pusat pelayanan kota dalam wilayah perkotaan dengan fungsi pelayanan berskala regional, dan kawasan perkotaan dalam wilayah kabupaten yang akan diterapkan sebagai pusat kegiatan. Kedua kawasan TOD sub-kota yang terdiri dari pelayanan pada TOD Sub-kota dalam wilayah daerah yang fungsi pada pelayanan berskala kota atau bagian kota dan kawasan perkotaan dalam wilayah daerah kabupaten yang akan ditetapkan sebagai pusat kegiatan, dan ketiga pada pusat pelayanan TOD lingkungan dalam wilayah daerah kota dengan fungsi pelayanan berskala lingkungan dan kawasan perkotaan dalam wilayah daerah kabupaten yang akan ditetapkan sebagai pusat kegiatan kawasan TOD lingkungan.

\section{Struktur Transit Oriented Development (TOD)}

Penerapan terhadap prinsip - prinsip Transit Oriented Development akan mempengaruhi struktur desain, Secara detail ada lima area dalam wilayah transit oriented development dan kawasan sekitarnya yang dipengaruhi oleh tujuh prinsip transite oriented development yang di kemukakan oleh (Calthorpe, 1993) yaitu fungsi publik (public uses) adalah Yaitu area publik yang dikhususkan dalam pelayanan bagi lingkungan kerja dan pemukiman di dalam TOD dan kawasan sekitar lokasi. Pusat area komersial (core commercial area). Area ini merupakan area pusat komersial dimana dalam sebuah rancangan konsep Transit Oriented Development (TOD) merupakan unsur yang sangat penting. Area ini di haruskan berada pada jangkauan 5 menit berjalan kaki dengan titik transit. Area pemukiman (residential area) yaitu Area pemukiman termasuk pemukiman berada pada jarak pejalan kaki dari area pusat komersial menuju titik transit. Kepadatan area pemukiman harus sesuai dengan tipe pemukiman yang ada termasuk single - family house, townhouse, condominium, dan apartement. Area sekunder (secondary area) yaitu Area sekunder berfungsi untuk akses langsung jalur sepeda atau pejalan kaki menuju titik transit area komersial. Terakhir adalah fungsi kawasan TOD yaitu Dalam kawasan TOD terdapat fungsi yang secara ekstensif bergantung pada kendaraan bermotor yang memiliki mobilitas untuk melakukan aktivitas 
intensitas perkantoran yang sangat rendah yang berada di luar kawasan TOD dan area sekunder.

\section{Transit Oriented Development (TOD) Sub-Urban}

Menurut The Geography Of Transport Systems ( https://transportgeography.org/), transit adalah suatu perpindahan antara satu moda transportasi menuju ke transportasi lain atau pada tempat lain, dalam pelaksaannya terdapat perbedaan antara lain sistem pelaksaannya dan letak tempat transit. Pada pelaksaannya sub-urban transit memiliki komponen yang jauh lebih detail untuk melakukan skala pelayanan.

\section{Prinsip Kawasan Tranist Oriented Development (TOD) Berdasarkan Peraturan Menteri ATR/BPN}

Menurut Peraturan Menteri ATR/Kepala BPN No. 16 tahun 2017 tentang Pedoman 19 Pengembangan Kawasan Berorientasi Transit, terdapat beberapa kriteria yang harus di penuhi dalam pengembangan TOD tersebut diantaranya, kawsaan yang berada pada simpul transit jaringan angkutan umum massal berkapasitas tinggi berbasis rel, dilayani minimal 2 moda transportasi, sesuai dengan arah pengembangan pusat pelayanan kegiatan dan berbasis kawasan campuran (mixed use).Pengembangan mixed use dapat dijelaskan ke dalam kawasan TOD yang diharapkan dengan berbagai macam kegiatan seperti perkantoran, perumahan, area bisnis komersial, ruang terbuka hijau yang terkoneksi dan saling terintegrasi dengan angkutan umum. TOD juga dapat memberikan penyediaan fasilitas publik yang mementingkan aksesibilitas bagi penghuni kawasan maupun pemakai moda transportasi masal yang diwujudkan dengan penyediaan jalur pedestrian dengan memberikan kenyamanan dalam berjalan kaki.

Menurut Undang - Undang penataan ruang nomor 24 tahun 1992 dapat didefinisikan bahwa kawasan adalah sebagai ruang kesatuan geografis beserta segenap unsur yang terkait dengan sistem ditentukan oleh aspek fungsional serta memiliki ciri - ciri khusus yang lebih spesifik. Contoh kawasan antara lain adalah kawasan lindung dan kawasan budidaya dalam suatu wilayah Provinsi, kawasan perkotaan dan kawasan perdesaan dalam suatu wilayah, kawasan perumahan, kawasan pusat kota, dan kawasan industri dalam suatu kota.

\section{Prinsip Transit Oriented Development (TOD) Berdasarkan Standard Intitute For Transportation and Development Policy (ITDP)}

TOD Standard yang dipublikasikan oleh Institute for Transportation and Development Policy (ITDP, 2017) adalah salah satu kriteria dan ukuran yang memberikan penilaian terhadap kesesuaian kosep TOD yang digunakan di seluruh dunia.TOD Standard yang dipublikasikan oleh ITDP memiliki 8 prinsip, berikut adalah penjelasan masing - masing prinsip berdasarkan standard ITDP untuk sebagai acuan evaluasi seperti berjalan kaki/walk, bersepeda/cyle, menghubungkan/connect, angkutan umum/transit, pembaruan/mix, memadatkan/density dan merapatkan/compact dan beralih/shift.

Dalam TOD Standard terdapat 3 peringkat sesuai dengan kriteria dan ukuran yang sudah ditentukan yang dinilai dari poin yaitu adalah: Peringkat 1 yaitu Gold Standard yang memiliki poin 86 - 100 dan memiliki pembangunan skala kota menjadi panutan global atau pusat kota dengan pembangunan yang berorientasi Transit inklusif. Peringkat 2 yaitu Silver Standard yang memiliki poin 71-85 dapat menandai proyek yang memenuhi hampir semua sasaran dari sebuah kinerja praktik. Dan peringkat 3 Bronze Standard memiliki poin 56-69 yang menandakan pembangunan proyek memenuhi mayoritas sasaran kerja dalam kinerja praktik terbaik. 


\section{Pengertian Transportasi}

Menurut (Miro, 2012), Transfortasi yaitu suatu perpindahan atau pergerakan osatu tempat ketempat lain dengan menggunakan alat tertentu sebagai media perpindahan. Penggunaan alat tranportasi timbul karena adanya suatu interaksi sosial ekonomi masyarakat. Untuk memenuhi kebutuhan hidupnya, manusia membutuhkan barang - barang pangan dan interaksi sosial dengan satu sama lain, sehingga diperlukan alat transfortasi untuk memenuhi kebutuhan dan aktivitas sosial. Hal ini dapat dipandang bahwa transportasi tidak dapat berdiri sendiri melainkan suatu kesatuan yang utuh dan menyeluruh sebagai sebuah sistem. Tamin, (2000)membagi sistem transportasi secara makro ke dalam empat sistem kategori transportasi mikro seperti sistem kegiatan, sistem jaringan, sistem pergerakan dan sistem kelembagaan.

\section{Pendekatan Penelitian}

Pada analisis penelitian evaluasif ini dilakukan dengan mengamati kawasan eksisting TOD Stasiun Cisauk dengan metode pengumpulan data primer untuk mendapatkan data objek studi secara langsung, survei lapangan, data sekunder, dan media elektronik. Pendekatan penelitian ini menggunakan deskriptif dengan menggunakan metode komperatif dan analisis Scorecard. Pendekatan penelitian akan mendapatkan hasil kesesuaian pengembangan TOD dengan standard Institute For Transportation Development Policy (ITDP) dan Peraturan Menteri ATR/BPN No.16 Tahun 2017 tentang Penataan Ruang dengan radius $400-800$ meter dari titik transit. Pada penelitian ini, kajian mengenai konsep Transit Oriented Development (TOD) di kawasan TOD Stasiun Cisauk menjadi data empirik yang menjadi kebenaran umum. Kemudian dirumuskan dengan teori - teori sebagai dasar penelitian yang berkaitan dengan konsep kesesuaian Transit Oriented Development (TOD) dengan Standard Intitute For Transportation Development Policy (ITDP).

\section{HASIL DAN PEMBAHASAN}

\section{Analisis Skoring}

Dalam analisis ini peneliti akan melakukan penilaian tentang pengembangan kawasan TOD Cisauk, penilaian ini dilakukan berdasarkan TOD Standard Scoring Detail untuk dapat menghitung kriteria TOD yang berada di seluruh dunia agar mengetahui kelas TOD suatu daerah dan apakah sudah sesuai dengan standar yang telah diatur oleh ITDP. Berikut adalah hasil skor TOD stasiun cisauk dengan perbandingan dari kriteria penilaian Standard Institute For Transportation Development Policy (ITDP).

Tabel 1. Hasil Skoring Penilaian TOD Stasiun Cisauk Berdasarkan Standard ITDP

\begin{tabular}{|c|c|c|c|c|}
\hline No & Prinsip TOD & Standar Matriks TOD & $\begin{array}{c}\text { Standar } \\
\text { Poin TOD }\end{array}$ & $\begin{array}{c}\text { Hasil Skor Penilaian } \\
\text { TOD Cisauk }\end{array}$ \\
\hline \multirow{5}{*}{1} & \multirow{5}{*}{ Berjalan/Walk } & Jalur pejalan kaki & 3 & 0 \\
\hline & & Penyebrangan jalan & 3 & 0 \\
\hline & & $\begin{array}{c}\text { Muka blok yang aktif } \\
\text { secara visual }\end{array}$ & 6 & 6 \\
\hline & & $\begin{array}{c}\text { Muka blok yang } \\
\text { permeabel }\end{array}$ & 2 & 0 \\
\hline & & $\begin{array}{c}\text { Peneduh dan tempat } \\
\text { Berteduh }\end{array}$ & 1 & 0 \\
\hline \multirow{3}{*}{2} & \multirow{3}{*}{ Bersepeda/Cycle } & $\begin{array}{c}\text { Jaringan Infrastruktur } \\
\text { bersepeda }\end{array}$ & 2 & 0 \\
\hline & & $\begin{array}{c}\text { Parkir sepeda di stasiun } \\
\text { angkutan umum }\end{array}$ & 1 & 1 \\
\hline & & $\begin{array}{c}\text { Parkir sepeda pada } \\
\text { bangunan }\end{array}$ & 1 & 0 \\
\hline
\end{tabular}




\begin{tabular}{|c|c|c|c|c|}
\hline No & Prinsip TOD & Standar Matriks TOD & $\begin{array}{l}\text { Standar } \\
\text { Poin TOD }\end{array}$ & $\begin{array}{c}\text { Hasil Skor Penilaian } \\
\text { TOD Cisauk }\end{array}$ \\
\hline & & $\begin{array}{c}\text { Akses sepeda ke dalam } \\
\text { Gedung }\end{array}$ & 1 & 0 \\
\hline \multirow[b]{2}{*}{3} & \multirow{2}{*}{$\begin{array}{l}\text { Menghubungkan/ } \\
\text { Connect }\end{array}$} & Blok - Blok Kecil & 10 & 6 \\
\hline & & $\begin{array}{l}\text { Keberpihakan Terhadap } \\
\text { Moda }\end{array}$ & 5 & 5 \\
\hline 4 & Angkutan Umum/Transit & $\begin{array}{c}\text { Jarak Berjalan Kaki } \\
\text { Menuju Angkutan } \\
\text { Umum }\end{array}$ & $\begin{array}{l}\text { Memenuh } \\
\text { i Standard } \\
\text { TOD }\end{array}$ & $\begin{array}{c}\text { Memenuhi Standard } \\
\text { TOD }\end{array}$ \\
\hline \multirow{3}{*}{5} & \multirow{3}{*}{ Pembauran/Mix } & $\begin{array}{l}\text { Tata Guna Lahan } \\
\text { Komplementer }\end{array}$ & 10 & 6 \\
\hline & & $\begin{array}{c}\text { Akses Terhadap Sumber } \\
\text { Makanan }\end{array}$ & 1 & 1 \\
\hline & & Hunian Terjangkau & 4 & 4 \\
\hline 6 & Memadatkan/Densify & $\begin{array}{c}\text { Kepadatan Tata Guna } \\
\text { Lahan }\end{array}$ & 15 & 7 \\
\hline \multirow[b]{2}{*}{7} & \multirow[b]{2}{*}{ Merapatkan/Compact } & Area Perkotaan & 10 & 10 \\
\hline & & $\begin{array}{c}\text { Pilihan Berangkutan } \\
\text { Umum }\end{array}$ & 5 & 5 \\
\hline \multirow{4}{*}{8} & \multirow{3}{*}{ Beralih/Shift } & Parkir Off-Street & 10 & 4 \\
\hline & & $\begin{array}{c}\text { Tingkat Kepadatan } \\
\text { Akses Kendaraan } \\
\text { Bermotor }\end{array}$ & 2 & 2 \\
\hline & & $\begin{array}{c}\text { Luasan Daerah Milik } \\
\text { Jalan Untuk Kendaraan } \\
\text { Bermotor }\end{array}$ & 8 & 0 \\
\hline & \multicolumn{2}{|c|}{ Total Poin } & 100 & 57 \\
\hline
\end{tabular}

Sumber : Hasil olahan data peneliti (2021)

Adapun penilaian dari hasil perhitungan matriks diatas yang dilakukan dengan menggunakan kriteria standar yang telah diterbitkan oleh Institute for Transportation and Development Policy (ITDP) Indonesia untuk mendapatkan penilaian Kawasan TOD stasiun cisauk, pada tabel diatas dapat dilihat bahwa kawasan TOD stasiun cisauk mendapatkan nilai total 57 poin dari hasil penilaian sempurna yaitu 100 poin, maka dapat diketahui bahwa katagori kelas Transit Oriented Development (TOD) Cisauk masuk ke dalam kawasan TOD Standard Bronze. Hal ini karena kawasan TOD Cisauk menurut hasil perhitungan yang dilakukan peneliti memperoleh poin antara $55-69$ poin. Dengan terdapatnya hasil poin tersebut TOD stasiun cisauk sudah sesuai dengan kriteria Standard Institute For Transportation Development Policy (ITDP). Walaupun kawasan TOD stasiun Cisauk masuk dalam klasifikasi Standard TOD Bronze tetapi masih menyisakan catatan untuk pengembangan Kawasan yang dimana dari penilaian matriks aspek berjalan kaki/walk merupakan aspek yang paling kecil dari hasil penilaian kriteria standar TOD, ada beberapa sebab rendahnya poin yang diperoleh karena aspek pejalan kaki yang dapat melindungi pejalan kaki belum begitu terpelihara dengan baik.

Pihak pengembang terlebih dahulu memprioritaskan aspek pejalan kaki pada kawasan area intermoda menuju stasiun cisauk, sedangkan fasilitas pejalan kaki yang aman dan nyaman pada area jalan BSD Raya Utama dan Jalan Raya Serpong - Lapan, akan tetapi pada Jalan Raya Serpong - Cisauk masih belum tertata rapih pada aspek berjalan/walk. Hal ini tidak sesuai dengan standar dari Institute for Transportation and Development Policy (ITDP) yang dimana pejalan kaki dapat menghidupkan aktivitas muka blok yang aktif secara visual. 
Tabel 2. Ringkasan Kesimpulan Hasil Penelitian berdasarkan TOD Standard Scoring Detail

\begin{tabular}{|c|c|c|}
\hline Aspek & Matriks & TOD Stasiun Cisauk \\
\hline \multirow{5}{*}{ Berjalan/Walk } & Jalur pejalan kaki & $\begin{array}{l}\text { Berdasarkan peraturan ITDP TOD karena } \\
\text { hanya memiliki jaringan jalur pejalan kaki } \\
\text { sebesar } 71 \% \text { dari persyaratan yang } \\
\text { diharuskan memiliki } 100 \% \text {. }\end{array}$ \\
\hline & Penyebrangan jalan & $\begin{array}{l}\text { Dapat disimpulkan bahwa kawasan TOD } \\
\text { Statsiun Cisauk Hanya memiliki } 78 \% \text { dalam } \\
\text { memenuhi persyaratan penyebrangan jalan } \\
\text { dari standar } 100 \% \text {. }\end{array}$ \\
\hline & $\begin{array}{c}\text { Muka blok yang aktif } \\
\text { secara visual }\end{array}$ & $\begin{array}{l}\text { Dari hasil survey dengan kriteria ITDP maka } \\
\text { Pada Kawasan TOD Cisauk segmen muka } \\
\text { jalan yang aktif secara visual yaitu } 100 \% \text {. }\end{array}$ \\
\hline & $\begin{array}{c}\text { Muka blok yang } \\
\text { permeabel }\end{array}$ & $\begin{array}{l}\text { Kawasan TOD Cisauk penilaian rata - rata } \\
\text { jumlah akses masuk muka blok permeabel } \\
\text { per } 100 \text { meter adalah } 1.4 \text { yang berarti kurang } \\
\text { dari } 3\end{array}$ \\
\hline & $\begin{array}{l}\text { Peneduh dan tempat } \\
\text { Berteduh }\end{array}$ & $\begin{array}{l}\text { Dari hasil survey dengan kriteria ITDP maka } \\
\text { Kawasan TOD Cisauk memiliki nilai 50\% dari } \\
\text { seluruh segmen jalan pada kesesuaian syarat } \\
\text { yaitu kurang dari } 75 \% \text {. }\end{array}$ \\
\hline \multirow{4}{*}{ Bersepeda/Cycle } & $\begin{array}{l}\text { Jaringan Infrastruktur } \\
\text { bersepeda }\end{array}$ & $\begin{array}{l}\text { TOD Cisauk memiliki persentase penilaian } \\
66 \% \text { untuk seluruh segmen jalan yang } \\
\text { memiliki kondisi bersepeda kurang dari } 90 \% \\
\text { dalam memenuhi standar. }\end{array}$ \\
\hline & $\begin{array}{l}\text { Parkir sepeda di } \\
\text { stasiun angkutan } \\
\text { umum }\end{array}$ & $\begin{array}{l}\text { TOD Cisauk memiliki } 1 \text { fasilitas parkir sepeda } \\
\text { terbatas dan aman dalam Kawasan TOD } \\
\text { Cisauk yang berarti sudah memenuhi } \\
\text { standar. }\end{array}$ \\
\hline & $\begin{array}{c}\text { Parkir sepeda pada } \\
\text { bangunan }\end{array}$ & $\begin{array}{l}\text { kawasan TOD Cisauk memiliki persentase } \\
\text { penilaian } 60 \% \text { dalam penyediaan fasilitas } \\
\text { tempat parkir sepeda pada bangunan yang } \\
\text { berarti kurang dari } 95 \% \text { untuk penyediaan } \\
\text { fasilitas parkir. }\end{array}$ \\
\hline & $\begin{array}{l}\text { Akses sepeda ke } \\
\text { dalam Gedung }\end{array}$ & $\begin{array}{l}\text { TOD Cisauk tidak terdapat peraturan daerah } \\
\text { atau undang - undang mengenai bangunan } \\
\text { terhadap akses masuk sepeda pada } \\
\text { bangunan. }\end{array}$ \\
\hline \multirow[b]{2}{*}{ Menghubungkan/Connect } & Blok - Blok Kecil & $\begin{array}{l}\text { Kawasan TOD Cisauk pada semua blok - blok } \\
\text { kecil memiliki panjang maksimum kurang } \\
\text { dari } 130 \text { meter. }\end{array}$ \\
\hline & $\begin{array}{l}\text { Keberpihakan } \\
\text { Terhadap Moda }\end{array}$ & $\begin{array}{l}\text { Berdasarkan perhitungan dari penilaian } \\
\text { diatas, maka ratio jumlah persimpangan } \\
\text { pejalan kaki dengan persimpangan } \\
\text { kendaraan bermotor sebesar } 2.5 \text { yang } \\
\text { berarti persimpangan kendaraan bermotor } \\
\text { lebih dari } 2 \text {. }\end{array}$ \\
\hline Angkutan Umum/Transit & $\begin{array}{l}\text { Jarak Berjalan Kaki } \\
\text { Menuju Angkutan } \\
\text { Umum }\end{array}$ & $\begin{array}{l}\text { Berdasarkan perhitungan dari penilaian } \\
\text { diatas, maka Jarak pada maksimum berjalan } \\
\text { kaki kurang dari } 1 \mathrm{~km} \text { menuju stasiun } \\
\text { angkutan umum massal atau berada pada } \\
400 \text { meter untuk menuju ke stasiun layanan } \\
\text { direct-service yang berarti sudah sesuai } \\
\text { dengan persyaratan standar TOD. }\end{array}$ \\
\hline
\end{tabular}




\begin{tabular}{|c|c|c|}
\hline Aspek & Matriks & TOD Stasiun Cisauk \\
\hline \multirow{3}{*}{ Pembauran/Mix } & $\begin{array}{l}\text { Tata Guna Lahan } \\
\text { Komplementer }\end{array}$ & $\begin{array}{l}\text { Berdasarkan perhitungan dari penilaian } \\
\text { diatas, maka proyek pembangunan } \\
\text { merupakan tata guna lahan komplementer } \\
\text { secara internal yang memiliki persentase } \\
\text { nilai 84\%. }\end{array}$ \\
\hline & $\begin{array}{l}\text { Akses Terhadap } \\
\text { Sumber Makanan }\end{array}$ & $\begin{array}{l}\text { Berdasarkan perhitungan dari penilaian } \\
\text { diatas, maka lebih dari } 80 \% \text { masyarakat dari } \\
\text { gedung - gedung yang berada di dalam } \\
\text { radius } 400-800 \text { meter pergi menuju sumber } \\
\text { makanan segar. }\end{array}$ \\
\hline & Hunian Terjangkau & $\begin{array}{l}\text { Berdasarkan perhitungan dari penilaian } \\
\text { diatas, persentase unit hunian terjangkau } \\
\text { adalah } 20 \% \text { pada hunian tempat tinggal. }\end{array}$ \\
\hline Memadatkan/Densify & $\begin{array}{c}\text { Kepadatan Tata Guna } \\
\text { Lahan }\end{array}$ & $\begin{array}{l}\text { Berdasarkan perhitungan dari penilaian } \\
\text { diatas, Memiliki nilai kesamaan pada } 3 \% \text { nilai } \\
\text { standar kepadatan pada daerah atau } \\
\text { memiliki rentan jarak tidak lebih dari } 5 \% \text {. }\end{array}$ \\
\hline \multirow[t]{2}{*}{ Merapatkan/Compact } & Area Perkotaan & $\begin{array}{l}\text { Berdasarkan perhitungan dari penilaian } \\
\text { diatas, terdapat pada bagian ke empat sisi } \\
\text { yang bersebelahan dengan titik transit sudah } \\
\text { terdapat area yang sudah terbangun } \\
\text { sebelumnya. }\end{array}$ \\
\hline & $\begin{array}{c}\text { Pilihan Pada } \\
\text { Berangkutan Umum }\end{array}$ & $\begin{array}{l}\text { Berdasarkan perhitungan dari penilaian } \\
\text { diatas, terdapat pada setiap jalur angkutan } \\
\text { umum massal dan memiliki kereta api rel, } \\
\text { BRT dan sebagainya. }\end{array}$ \\
\hline \multirow{3}{*}{ Beralih/Shift } & Parkir Off-Street & $\begin{array}{l}\text { Berdasarkan perhitungan dari penilaian } \\
\text { diatas, parkiran non-esensial setara dengan } \\
\text { nilai } 17 \% \text { atau kurang dari } 20 \% \text { nilai luasan } \\
\text { area proyek. }\end{array}$ \\
\hline & $\begin{array}{l}\text { Tingkat Kepadatan } \\
\text { Akses Kendaraan } \\
\text { Bermotor }\end{array}$ & $\begin{array}{l}\text { Berdasarkan perhitungan dari penilaian } \\
\text { diatas, Pada tingkat kepadatan akses } \\
\text { kendaraan bermotor dalam rata rata } 0.085 \\
\text { per } 100 \text { meter atau < } 2 \text { per } 100 \text { meter. }\end{array}$ \\
\hline & $\begin{array}{l}\text { Luasan Daerah Milik } \\
\text { Jalan Untuk } \\
\text { Kendaraan Bermotor }\end{array}$ & $\begin{array}{l}\text { Berdasarkan perhitungan dari penilaian } \\
\text { diatas, Pada luasan untuk kendaraan } \\
\text { bermotor yang memiliki nilia persentase } \\
\text { sebesar } 22 \% \text { atau lebih dari } 20 \% \text { lahan area } \\
\text { proyek. }\end{array}$ \\
\hline
\end{tabular}

Sumber : Hasil Olahan Data Penelitia (2021)

\section{PENUTUP, KESIMPULAN DAN SARAN}

\section{Kesimpulan}

(1) Pada kawasan TOD stasiun cisauk memiliki potensi untuk menjadikan TOD menjadi berkembang lebih pesat karena berdasarkan budaya masyarakat perkotaan Indonesia mayoritas masih mementingkan kendaraan pribadi dalam melakukan akstivitas seharihari hal ini dapat diartikan mobilitas masyarakat Indonesia sangat tinggi dalam melakukan aktivitas kegiatan setiap harinya dan pemerintah selalu melakukan pembangunan akses jalan kendaraan umum yang dekat dengan rumah - rumah yang memiliki lokasi tapak strategis dan tertata menjadikan setiap penghuni lebih mementingkan kendaraan pribadi, akan tetapi terdapat juga permasalahan di kawasan TOD stasiun cisauk karena banyaknya masyarakat Kawasan TOD tersebut memiliki hunian tapak yang tidak tertata dikawasan terserbut yang seharusnya bisa menjadikan 
pembangunan fasilitas atau pusat kegiatan jika lahan tersebut dialihkan menjadi hunian pembangunan vertikal.

(2) Berdasarkan penilaian tersebut Kawasan TOD Stasiun Cisauk mendapatkan nilai total 57 poin dari hasil penilaian sempurna yaitu 100 poin, maka kawasan TOD Stasiun Cisauk dapat diartikan sudah sesuai dengan peraturan Institute Transportation Development Policy dan kementerian ATR/BPN. TOD stasiun cisauk mendapatkan katagori pembangunan TOD Bronze telah disesuaikan dengan standard TOD yang memiliki nilai poin $55-69$ poin sebagai proyek pembangunan yang berorientasi angkutan umum dan transit.

(3) Berdasarkan rencana kota pada Peraturan Daerah Kabupaten Tangerang, maka lahan sekitar Stasiun memiliki izin untuk melakukan pembangunan skala vertikal dikarenakan lahan sekitar Stasiun memiliki stasiun lahan zona campuran dan dalam lokasi tapak diatas legalitas lahan tersebut telah dipertanggung jawabkan oleh hak atas lahan yang dimiliki PT. Kereta Api Indonesia (PT.KAI). Dalam pengembangan Kawasan TOD Stasiun tersebut PT. KAI menunjuk Hak Pengelola KRL Commuter Line sebagai penanggung jawab hak pengelola Stasiun Cisauk. Tanah tersebut memiliki status lahan Hak Guna Bangunan diatas hak pengelola.

(4) lokasi objek studi peneliti masih terbilang sudah baik, dikarenakan akses untuk menuju lokasi objek studi dapat dicapai dengan menggunakan KRL Commuter line yang bertujuan Tanah Abang - Maja, Tanah Abang Parung Panjang, Tanah Abang - Serpong yang langsung menuju ke Stasiun Cisauk, untuk jarak tempuh dari Stasiun Tanah Abang menuju Stasiun Cisauk hanya memakan waktu 40 menit, apabila pengguna ingin melakukan aktivitas keluar atau menuju Kawasan TOD Stasiun Cisauk bisa menggunakan kendaraan pribadi atau transportasi umum yang menjadi solusinya dikarenakan untuk menuju ke lokasi TOD Stasiun Cisauk dapat terbilang mudah, karena sudah terdapatnya Jalan tol Jakarta - Merak dengan pintu keluar serpong dan Jalan tol Serpong - BSD dengan pintu keluar rawabuntu, Akses masing - masing tol tersebut dapat dicapai dengan waktu tempuh 16 menit dengan menggunakan kendaraan.

\section{Saran}

\section{Pemerintah Kabupaten Tangerang}

Pada perhitungan dari analisis skoring berdasarkan standard 3.0 ITDP, kawasan TOD stasiun cisauk mendapatkan penilaian 57 poin dari hasil sempurna yaitu 100 poin. Dalam hal ini TOD Stasiun Cisauk mendapatkan katagori pembangunan TOD kelas bronze yang berarti sudah memenuhi standar TOD, akan tetapi menurut peneliti TOD Stasiun Cisauk harus lebih ditambahkan lagi prasarana yang berada di Kawasan TOD tersebut khususnya praasarana pada prinsip walk dikarenakan pada penilaian prinsip walk kurang banyak prasana yang ada pada kondisi eksisting menjadikan penilaian walk TOD Stasiun Cisauk memiliki nilai paling rendah diantara prinsip TOD lain. Hal yang diharapkan pada Pemerintah Kabupaten Tangerang melihat kondisi tersebut agar menjadikan TOD Stasiun Cisauk menjadi lebih baik dan masuk ke dalam katagori Pembangunan TOD kelas Gold yang memiliki poin 85- 100 poin, pada kondisi eksisting peneliti melihat TOD Stasiun Cisauk memiliki potensi untuk menjadi pembangunan TOD kelas gold dikarenakan letak lokasi TOD Stasiun Cisauk terbilang sangat strategis dalam mencapai aktivitas kegiatan untuk menuju pusat - pusat kota dan TOD Stasiun Cisauk berada ditengah tengah daerah administrasi antara Tangerang Selatan dan Kabupaten Bogor, hal ini dapat menjadikan daerah cisauk menjadi hidup dan meningkatkan perekonomian masyarakat yang berada di Kawasan TOD tersebut.

\section{Pengembang (Sinarmas Land BSD CITY)}

Saran untuk pengembang yaitu lebih di fokuskan kembali kepada prasarana pada prinsip walk dalam kriteria TOD dan muka bangunan aktif secara visual, inti dari fungsi TOD yaitu 
selain mengurangi kemacetan jalan karena penggunaan mobilitas yang sangat tinggi, TOD dapat menghidupkan fungsi muka bangunan menjadi aktif dalam hal kegiatan aktivitas perekonomian masyarakat sekitar stasiun cisauk, karena pada kondisi eksisting prasana yang berada di Jalan Raya Cisauk Lapan belum terdapat indikator pada fasilitas pejalan kaki dan jalur pesepeda, jika pengembang bekerjasama dengan pihak pemerintah daerah yaitu Kabupaten Tangerang akan menjadikan lebih baik dikarenakan jalan jalan yang berbatasan dengan muka blok bangunan aktif secara visual dapat menimbulkan aktivitas perekonomian masyarakat.

\section{Akademisi}

Objek dari penelitian ini masih sangat terbatas, dimana peneliti hanya melakukan penelitian pada matrik - matrik analisis yang telah di tentukan oleh Standard Institute for Transportation and Development Policy (ITDP), Objek analisis lainnya seperti mengkomparasi antara aturan pemerintah daerah dengan Standard Institute for Transportation and Development Policy (ITDP) untuk kawasan TOD belum secara menyeluruh peneliti analisis. Diharapkan para akademisi mendatang dapat menilai TOD Stasiun Cisauk menjadi masuk ke dalam kriteria kelas Gold pada standar ITDP dikarenakan Kawasan TOD Stasiun Cisauk memiliki potensi lebih baik untuk mendapatkan nilai yang sangat sempurna dan lokasi TOD Stasiun Cisauk dapat dibilang sangat startegis untuk menuju pusat - pusat kegiatan.

\section{REFERENSI}

Aracil, P. F. (2017). Tod ( Transit-Oriented Development ) Model : an International Approach and. 477-482.

Banister, D. (2011). The trilogy of distance, speed and time. Journal of Transport Geography, 19(4), 950-959. https://doi.org/10.1016/j.jtrangeo.2010.12.004

Calthorpe, P. 199. (1993). The next American metropolis: Ecology, community, and the American dream. Princeton architectural press. In The Next American Metropolis: Ecology, Community, and the American Dream (Vol. 1, Issue August, pp. 117-125). ublished by Princeton Architectural Press 37 East 7th Street New York, New York 10003 C 1993 Princeton Architectural Press.

Dittmar, Hank, and Gloria Ohland. (2012). The new transit town: Best practices in transitoriented development. In Island Press, 2012.

Garreau, J. 2011. (2011). Edge city: Life on the new frontier. Anchor, 2011. In Praise for Edge City "To look around at the convulsing of American cities is to won- der WHAT'S GOING ON? (p. 2011).

Geurs, K. T., \& van Wee, B. (2004). Accessibility evaluation of land-use and transport strategies: Review and research directions. Journal of Transport Geography, 12(2), 127-140. https://doi.org/10.1016/j.jtrangeo.2003.10.005

Handinoto, P. H. S. (1996). Perkembangan kota \& arsitektur kolonial Belanda di Malang. In Perkembangan kota \& arsitektur kolonial Belanda di Malang (Vol. 26, Issue 4, pp. 551556).

Hartshorn, T. A. (1992). (1992). Interpreting the City. New York: Wiley. New York: Wiley. ITDP. (2017). TOD Standard. TOD Standard, 3, 61. www.ITDP.org 
